\title{
TARIN, Adrián (coordinador) Miradas libertarias, 2015, Editorial Catarata, Madrid, 237 páginas. ISBN 978-84-9097-045-4.
}

\section{E. Martín Cuesta}

Instituto Interdisciplinario de Economía Política de Buenos Aires - Universidad de Buenos Aires y Consejo Nacional de Investigaciones Científicas y Técnicas (IIEP-BAIRES-UBA/CONICET), Argentina

martincuesta@conicet.gov.ar

Esta obra se publica bajo licencia Creative Commons Atribución-NoComercial-CompartirIgual 4.0 Internacional

\section{(cc) BY-NC-SA}

Esta obra colectiva, coordinada por Adrián Tarín, propone un acercamiento desde diferentes perspectivas y temas al ideario anarquista y/o libertario. El prólogo de Carlos Taibo posiciona al lector en una clave compleja, ubicando la obra y los ocho capítulos que lo integran en el marco teórico e ideológico acertado, facilitando una lectura atenta y enriquecedora del conjunto de trabajos. Estos, por su diversidad de análisis y enfoques, podrían leerse en el orden propuesto. Aunque también es un desafío intelectual interesante reordenar la lectura según afinidades temáticas o abordajes. La calidad de los textos, así como la diferente pertenencia y recorrido intelectual de los autores, lo permite sobradamente.

Los trabajos presentados en el texto proponen un "delicioso" desafío intelectual al lector. El pensamiento libertario en los tiempos actuales tiene mucho que ofrecer, en contrario a lo que han sostenido quienes propusieron su antigüedad u obsolescencia. Los problemas y características de la sociedad del siglo XXI, llamada "posmodernidad" o "post-posmodernidad", ameritan la revitalización de las miradas libertarias.

Este es uno de los temas del capítulo 3 (de Francisco de los Cobos), en que se analiza la configuración de los vínculos sociales actuales en relación con el pensamiento anarquista. La relación es importante, revelando al interior del entramado social rupturas y disrupciones en donde el ideario del anarquismo tiene mucho para decir, y explicar.

Teniendo en cuenta lo anterior, el capítulo 1 (de Juan Rodríguez et al.), ofrece varias líneas interesantes de trabajo, abordando los problemas de la investigación social desde la perspectiva libertaria. Este es un interesante aporte, que llama a la reflexión profunda sobre la tarea de los investigadores.

En el capítulo 2 (de Alejandra Ríos Ramírez) se presenta uno de los tópicos clásicos, y centrales, del anarquismo: el poder. Estas páginas son una de las llaves que posibilitan la lectura del resto de la obra. El análisis del poder en tanto concepto, entendiéndolo como stock o como flujo, lo cual no es una distinción menor, tiene una profusa, abundante e interesante bibliografía. El 
colaborador a cargo de este capítulo desarrolla de manera clara, precisa y sustentada la relación entre el poder y el pensamiento anarquista.

El tema del poder es uno de los clivajes centrales a partir del cual se pueden abordar el resto de los capítulos: urbanismo, feminismo, liderazgo, violencia y derecho.

El capítulo de urbanismo y anarquismo (de Iván Díaz Parra) aporta un interesante análisis desde la geografía de la conformación del espacio urbano como construcción y reflejo de las relaciones de poder en la sociedad. Introduce con una presentación de la acción sobre el espacio urbano desde el pensamiento anarquista, desde la visión de los pensadores anarquistas (como Kropotkin y Reclus, entre otros). Así, la urbe capitalista es entendida como "un instrumento de la acumulación de capital". Y las categorías de espacio, abundancia, escasez o mercantilización son presentadas en la clave del pensamiento anarquista, siendo explicativas de las realidades urbanas actuales.

El feminismo en clave libertaria es el objeto del capítulo 5 (de María Teresa Fernández Ostos y Belén Zurbano), asimilando movimiento libertario con anarquismo. En parte realizando un recorrido histórico, y completando con el análisis teórico, las autoras critican que no todos los pensadores anarquistas entendieron (o por lo menos no acabadamente) el tema de la igualdad de género o la igualdad sexual. Otro aporte interesante del trabajo es la historia de la agrupación "mujeres libres". En gran medida, se deja en claro la relación de poder implícita en las relaciones de género y sexuales.

El mismo tema del poder, pero desde otro ángulo y con otra serie de dificultades teóricas y analíticas, está presente en el capítulo 6, a cargo de José Manuel Rivas: el liderazgo. Pocos temas son más desafiantes para el pensamiento libertario o anarquista como este. José Manuel Rivas, con un importante apoyo teórico y bibliográfico, aborda este problema desde un enfoque biográfico: la vida y obra de Buenaventura Urruti. A partir del análisis del caso empírico, se demuestra que incluso las condiciones de construcción del liderazgo (que se presentan y estudian una por una) no son incompatibles con el ideal libertario.

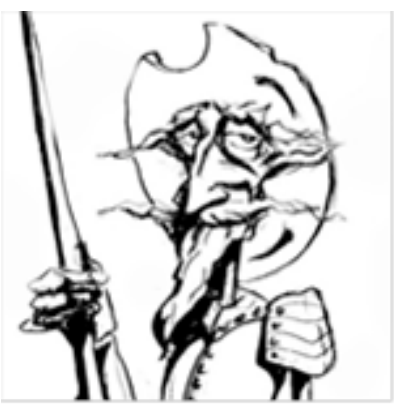

Otro tema "urticante" es la vinculación con la violencia, que es el centro del capítulo a cargo de Adrián Tarín. Para llegar al tema en profundidad, se complejiza el análisis a partir del concepto de hegemonía (en parte de Antonio Gramsci). Este, con deslizamiento hacia el discurso, permite al autor enmarcar el concepto de violencia en la acción política. De esta manera, observa el tema desde varios ángulos posibles, y en relación con los ideales anarquistas y/o libertarios, resolviendo más que adecuadamente la interacción.

El trabajo de cierre, de Aitor Jiménez González, abreva en una profusa bibliografía e historiografía para descorrer el velo que presenta como universal y atemporal la "Historia del Derecho". Aquí aparece con toda su fuerza el 
problema del poder, y el autor analiza una de sus variantes: el colonialismo. La argumentación es sólida e interesante, dando como resultado un capítulo sólido acerca de las relaciones de poder implícitas en la construcción historiográfica del derecho como concepto.

Para ofrecer un párrafo a manera de síntesis, es una obra sumamente interesante, que recoge y presenta diferentes perspectivas, miradas y abordajes sobre las posiciones anarquistas y/o libertarias en el siglo XXI. Dadas las condiciones económicas y sociales de la segunda década de este siglo, su lectura es más que recomendable. 